\title{
As políticas neoliberais e o pragmatismo gerencial na educação pública paranaense
}

\author{
The neoliberal politics and the managerial pragmatism in the public \\ education of Paraná
}

\section{Políticas neoliberales y pragmatismo gerencial en la educación pública en Paraná}

\author{
Ademir Aparecido Pinhelli Mendes ${ }^{1}$ \\ Centro Universitário Internacional Uninter, Programa de Pós-graduação Profissional em \\ Educação e Novas Tecnologias - Mestrado e Doutorado, Professor Titular. \\ https://orcid.org/0000-0003-4929-9544 \\ Geraldo Balduíno Horn ${ }^{2}$ \\ Universidade Federal do Paraná, Programa de Pós-graduação em Educação - Mestrado e \\ Doutorado, Professor Titular. \\ https://orcid.org/0000-0003-1056-4822 \\ Edson Teixeira de Rezende ${ }^{3}$ \\ Faculdade de Ensino Superior do Paraná, Professor. \\ https://orcid.org/0000-0002-5044-8167
}

Resumo: Trata-se de um estudo documental, com o objetivo de analisar as politicas neoliberais que vêm sendo implantadas pelo governo do Paraná. Para tal, parte-se de três problemas fundamentais: (i) as políticas neoliberais ganharam força no Paraná a partir de 2010, com ○ Governo Beto Richa provocando um completo rompimento do espírito republicano e democrático; (ii) ocorreu no Paraná, em sintonia com o impeachment de 2016, uma total desresponsabilização do Estado para com a coisa (res)pública e uma ampliação da perda de direitos; (iii) está em curso uma nova concepção de gestão educacional - gerencialismo e pragmatismo protagonizados por institutos e fundações. Analisam-se os desdobramentos das políticas educacionais no Paraná com a implantação do modelo de gestão educacional orientado pelo Guia de Tutoria Pedagógica, da Fundação Itaú Social (2014), e 15 roteiros de tutoria elaborados e lançados pelo Departamento de Acompanhamento Pedagógico da Secretaria de Estado de Educação do Paraná. Entre outros aspectos, o estudo conclui que as atuais

Doutor e Mestre em Educação pela Universidade Federal do Paraná

Pós-doutor em Educação pela Universidade Federal de Santa Maria; Doutor em Educação pela Universidade de São Paulo.

Doutor em Educação pela Universidade Federal do Paraná; Mestre em Educação pela Pontificia Universidade Católica do Paraná. 
politicas educacionais no estado destroem significativamente a autonomia pedagógica das escolas e não melhoram as condições de trabalho docente na rede pública paranaense.

Palavras-chave: Políticas neoliberais. Pragmatismo gerencial. Trabalho pedagógico. Educação básica.

Abstract: It is a study of documentary based on three fundamental premises that analyzes the neoliberal politics that have been implanted in Paraná in the last years: (i) the neoliberalism in Paraná won new force since 2010, with the government of Beto Richa, provoking a complete breaking of the republican and democratic spirit; (ii) it happened in Paraná, in line with the impeachment of 2016, a total disclaimer of the State to the (res)public thing and an enlargement of the loss of rights;; (iii) it is in course a new conception of education administration - managerialism and pragmatism played by institutes and foundations. The text analyzes the unfoldings of the education politics in Paraná with the implantation of the education administration's model guided by a document of Fundação Itaú Social (2014) elaborated in business and market language, that is mainly in charge of the results of the institutional evaluations of wide climbs, as Prova Brasil and Prova Paraná. For this study, fifteen guardianship itineraries were analyzed, which were elaborated and released by the Section of Pedagogic Attendance of the State Department of Education. Among other aspects, the study concludes that the education politics that have been implemented in Paraná destroy the pedagogic autonomy significantly and they don't improve the conditions of educational labor in the public net of Paraná.

Keywords: Neoliberal politics. Managerial pragmatism. Pedagogical labor. Basic education.

Resumen: Es un estudio documental, teniendo como el objetivo analizar las politicas neoliberales que ven siendo introducidas por el gobierno del Paraná. Para eso, usa tres problemas fundamentales: (i) las políticas neoliberales ganando la fuerza en el Paraná en año 2010, con el gobierno del Beto Richa, provocando una ruptura del espíritu republicano y democrático; (ii) ocurrió en el Paraná, una combinación perfecta con el proceso de destitución (impeachment) del año 2016, una total omisión con el Estado y con las cosas públicas y una ampliación de daños del derecho, (iii) está en progreso una nueva concepción de gestión educacional empresarial y pragmático protagonizado por los institutos y fundaciones. Análisis los desarrollos de las politicas educacional orientado por el Guía Tutoría Pedagógica, de la fundación Itaú Social (2014) y quince guiones de orientación elaborados y lanzados por el departamento del apoyo pedagógico de la secretaría de educación del estado de Paraná. Entre otros aspectos, el estudio concluye que políticas educativas actuales en el estado destruyen significativamente la autonomía pedagógica de las escuelas y no mejoran las condiciones del trabajo de los profesores de la rede publica paranaense.

Palabras claves: Políticas neoliberales. Pragmatismo gerencial. Trabajo pedagógico. Educación básica.

Recebido em 1 de setembro de 2019

Aceito em 29 de abril de 2020

Publicado em 04 de junho de 2020 


\section{INTRODUÇÃO}

A análise da problemática da implementação das políticas neoliberais que vêm sendo implantadas nos últimos anos no Brasil e, em especial, no Paraná precisa levar em conta que está em curso, na noosfera do universo da gestão pública hodierna, uma defesa intransigente da privatização e gerenciamento da educação pública, principalmente por meio de repasse de dinheiro público para o setor privado, bem como da contratação de assessorias de institutos e fundações.

De acordo Mendes (2008), a transferência do dinheiro público para o setor privado já era um problema observado no Paraná em meados dos anos 1990 na gestão do Governo Lerner (1995-2002), mas foi na governança do Partido Social Democrata Brasileiro (PSDB), a partir de 2010, com Beto Richa, que as políticas de caráter neoliberal tiveram impulso, com a implementação de um novo modelo de gestão educacional concebido a partir da visão empresarial e do mercado (SOUSA, 2013). Esse modelo também foi adotado e vem sendo atualmente aplicado pela Secretaria de Estado da Educação do Paraná (SEED-PR) do Governo Ratinho Júnior (2019-atual). Trata-se de uma política educacional perversa, focada tão somente nos resultados das avaliações institucionais de larga escala, como Prova Brasil, que produz o Índice de Desenvolvimento da Educação Básica (IDEB), e recentemente a Prova Paraná, que busca estimular o empreendedorismo gerencial dos diretores das escolas para a elevação dos índices de avaliações externas que aferem qualidade à educação, sem modificar as condições de trabalho dos profissionais da educação e de ensino e aprendizagem no interior das escolas.

Houve, principalmente nos últimos anos, um forte desgaste para os trabalhadores da educação o qual, por conseguinte, já provocou inúmeras manifestações, protestos e ocupações de escolas por parte de estudantes de ensino médio e superior no Paraná e em todo o País. Em contrapartida, os governos (nacional e estadual) reagiram com agressões e violência de toda ordem. 0 rompimento do modelo democrático de gestão e a desresponsabilização do Estado ocorrem, principalmente, pela adoção de uma política pragmática e de natureza gerencial, implementada por institutos e fundações educacionais na definição de políticas educacionais, sem debate público das medidas adotadas (SAVIANI, 2020). Evidências da problemática analisada neste artigo podem ser encontradas nos convênios celebrados entre o governo do Paraná e institutos, fundações e organizações não governamentais para realizar nas escolas atividades pedagógicas inerentes às atribuições do Estado, como reforço escolar, atividades de contraturno, consultorias pedagógicas para 
implementação da Base Nacional Comum Curricular (BNCC), produção de materiais didáticos, uso de tecnologias e inteligência educacional, etc. (PARANÁ, 2019c, 2019a).

A partir da problemática apresentada, o objetivo geral deste artigo consiste em analisar o documento Guia de tutoria pedagógica, da Fundação Itaú Social (2014), e os roteiros de tutoria pedagógica, da SEED-PR (PARANÁ, 2019b), a fim de evidenciar o pragmatismo gerencial da política educacional de natureza neoliberal em vigor atualmente no Estado do Paraná.

0 caminho metodológico adotado para consecução dos resultados apresentados neste artigo foi a análise de documentos coletados pelos pesquisadores. 0 primeiro documento analisado foi o Guia de Tutoria Pedagógica, da Fundação Itaú Social (2014), o qual foi elaborado em linguagem empresarial e de mercado e se ocupa, principalmente, dos resultados das avaliações institucionais de larga escala. Outro grupo de documentos analisados foram os 15 roteiros de tutoria pedagógica elaborados e lançados pelo Departamento de Acompanhamento Pedagógico da Secretaria de Estado de Educação (PARANÁ, 2019b), para realizar o monitoramento e supervisão do trabalho pedagógico nas escolas estaduais. Os roteiros de tutoria pedagógica são utilizados por professores-tutores designados pela SEEDPR para visitar semanalmente um conjunto de escolas, por ela tutoradas, e implementar as políticas pedagógicas emanadas da mantenedora.

0 artigo está organizado em duas partes, além desta introdução. A primeira contextualiza histórica e conceitualmente a política educacional em vigor no Estado do Paraná e seu caráter neoliberal. Já a segunda apresenta um diagnóstico do processo de reorganização do trabalho pedagógico que vem sendo implementado pela SEED-PR por meio da chamada tutoria de orientação pedagógica.

\section{A POLÍTICA EDUCACIONAL NEOLIBERAL: DESRESPONSABILIZAÇÃO DO ESTADO}

No fim da década de 1980, com a consolidação da abertura política, as discussões sobre o currículo escolar e o papel da educação na transformação social, política e econômica da sociedade ganharam força na educação brasileira. No Estado do Paraná, o resultado desse processo foi materializado no Currículo Básico, construído por professores da SEED-PR a partir da segunda metade da década de 1980 e, principalmente, entre os anos de 1990 e 1994. Por razões políticas, o documento não foi utilizado nas escolas, pois, em 1995, o Governo Lerner instituiu um novo projeto de educação no estado (NODA; GALUCH, 2018).

Mendes (2008) analisa que essas políticas educacionais de inspiração neoliberal começaram a ser implantadas a partir de 1995, marcadas pela minimização do Estado no 
gerenciamento da educação, com o repasse de suas ações para outras instituições e indivíduos. Esse modelo gerencial foi responsável, até 2002, pela implementação de medidas que reforçavam a terceirização e, por conseguinte, a precarização e mercantilização da educação. Durante esse período, a escola pública paranaense foi abandonada à sua própria sorte e passou a assumir funções distantes das necessidades e dos objetivos de uma escola pública, democrática e republicana, como concebida pela Constituição Brasileira de 1988 e pela Lei n. 9394/96, que definiu as Diretrizes e Bases para a Educação Nacional (LDBEN).

Em pesquisa de doutorado, Horn (2002) encontrou evidências de que esse período foi marcado por uma grande ausência de discussões curriculares, com a adoção dos Parâmetros Curriculares Nacionais do Ensino Médio (PCNEM) como definidores dos conteúdos a ser trabalhados em sala de aula em todas as disciplinas. Na esteira dessa pragmática política curricular, a SEED-PR também evitou realizar concurso para contratação de professores habilitados, o que contribuiu com a precarização das condições e exploração do trabalho (Processo Seletivo Simplificado (PSS) - contratações temporárias). Ademais, não ocorreu investimento em materiais de apoio didático-pedagógico adequados para o trabalho com o estudante do ensino médio; em geral, os professores pautavam seu ensino em manuais e livros didáticos disponíveis no mercado, como assevera Vieira (2012) ao também investigar esse período governamental no Paraná.

Jesus e Gomide (2008) apontam que, nesse período, a escola pública deparava-se com a ausência de formação continuada mínima adequada para seus professores. Os poucos cursos ofertados não tinham como objeto o conhecimento ou a disciplina de formação ou atuação dos professores. A formação continuada era voltada para programas motivacionais e de sensibilização, sem nenhuma preocupação com a produção docente - do crescimento profissional e intelectual do professor.

\footnotetext{
Considerando-se particularmente a questão da participação da comunidade dentro da escola, é interessante observar que, sob o argumento da gestão participativa e compartilhada, o Estado exime-se cada vez mais de suas responsabilidades para com as politicas sociais, entre elas, as relacionadas ao sistema escolar. Os resultados desse processo, além de reforçar o desprestígio à formação específica e qualificada dos docentes, conduz a uma formação diferenciada, fragilizada e fragmentada destes profissionais desconsiderando-se a importância da formação científica dos povos dos paises pobres. (JESUS; GOMDE, 2008, p. 8).
}

Esse conjunto de acontecimentos não ocorreu por mero acaso ou descuido das políticas educacionais; houve uma explícita intencionalidade nisso tudo. A ausência de ações efetivas em favor do desenvolvimento de políticas educacionais foi, na verdade, parte da política de reforma do ensino médio, encampada pelo Ministério da Educação (MEC) e Conselho Nacional 
de Educação (CNE), uma política voltada para o esvaziamento da discussão pedagógica. Assim, - que se configura como ausência de políticas efetivas para o desenvolvimento escolar constituiu, na verdade, em parte do projeto de colonização do pensamento pedagógico, desenvolvido no bojo das reformas educacionais neoliberais patrocinadas pelo capital transnacional e implementadas com apoio e assessoria de intelectuais encarregados de produzir teorias que justificassem e legitimassem a reforma do sistema de ensino, conforme registrado por Gomide (2010).

De acordo com normativas do MEC, a concepção e a organização do currículo deveria obedecer e reforçar a lógica que regia a produção de bens e mercadorias definida pelo modo de produção capitalista, isto é, formar individuos empreendedores e flexíveis capazes de adaptar-se às mudanças do mercado de trabalho, organizado e dirigido pela perspectiva das grandes corporações. "A ideologia veiculada faz crer que 'moderno' é o sistema de ensino orientado pelo e para o mercado, enquanto tradicional, 'arcaico' é todo projeto construído em torno de propósitos menos 'eficientes.' (TIRADENTES, 2018, p. 28).

0 objetivo era formar um sujeito que se adaptasse a um projeto de sociedade cuja finalidade era a produção em constante processo de mudança. Mas como lidar com o sujeito real e não com aquele idealizado pelas políticas educacionais? Esse foi o principal desafio enfrentado pelas duas gestões do governo Requião (2003-2010), que sucedeu o período Lerner - principal responsável pela implementação de um conjunto de ações que atendiam à cartilha neoliberal de gerenciamento da gestão pública no Paraná (ANDRADE, 2012; JESUS; GOMIDE, 2008).

Entre 2003 e 2010, no Estado do Paraná, foram produzidas as Diretrizes Curriculares para a Educação Básica e formação continuada centrada na área de atuação docente e também o livro didático público para todas as disciplinas do ensino médio, assim como foram realizados vários concursos públicos para nomeação de professores de diversas áreas do conhecimento, amparados por um plano de carreira do magistério de demais profissionais da educação. Essas ações indicaram uma radical mudança de rumo do projeto político e educacional neoliberal (MENDES, 2008).

Tratava-se da construção, em sintonia com o governo federal, de politicas que reforçassem a escola pública, universal, gratuita, democrática e socialmente referenciada. Em 2006, o MEC publicou um novo texto, como alternativa ao PCNEM, com o título Orientações Curriculares Nacionais (OCN), para todas as disciplinas do ensino médio. As OCN procuravam desincumbir-se de uma possível conceituação neoliberal de competência (MENDES, 2008).

No entanto, nos anos seguintes a 2011, ocorreu uma derrocada do modelo democrático, participativo e progressista. Houve uma substantiva reclusão nas políticas de inclusão, diminuição dos editais de concurso público para professores, aumento do número 
de professores contratados pelo sistema de Processo Seletivo Simplificado (PSS), diminuição da carga horária dos professores destinada para hora-atividade, não cumprimento dos compromissos assumidos com relação às demandas da categoria, como, por exemplo, a reposição dos índices de inflação no salário do funcionalismo, plano de carreira, etc. (VIEIRA, 2012).

0 período de oito anos em que Beto Richa (2011-2018) esteve no comando do governo representou a consolidação das políticas educacionais de caráter neoliberal no Paraná. A formação continuada de professores ocorreu essencialmente em ambiente virtual, com temáticas pontuais e fragmentadas ofertadas eventualmente aos professores, sem nenhum critério acadêmico e de continuidade. E destruiu as equipes pedagógicas organizadas por áreas do conhecimento e que tinham a responsabilidade de manter vivo o debate pedagógico nos núcleos regionais e nas escolas. Como já apontado, tratava-se de um modelo de gestão educacional concebido a partir da visão empresarial e do mercado, uma política artificial focada tão somente nos resultados das avaliações institucionais de larga escala, como Prova Brasil e Prova Paraná, sem modificar as condições de trabalho dos profissionais da educação ou a de ensino e aprendizagem no interior das escolas (DAMETTO, 2017).

A Constituição Federal de 1988 prevê, em seus artigos 205 e 206, que a gestão da escola pública seja democrática e um direito social de todos os brasileiros. No art. 14, incisos e ll, a LDB preconiza a participação dos profissionais da educação na gestão democrática da educação (BRASIL, 1988). Diante dessa legislação, observa-se que uma das características da gestão educacional é a participação coletiva e democrática, seja ela nas esferas de decisão da política educacional em nível governamental seja em nível da construção do Projeto Político-Pedagógico (PPP) de cada unidade escolar, bem como nas atividades inerentes ao processo de ensino e aprendizagem.

Libâneo, Oliveira e Toschi (2012) classificam a gestão escolar em quatro grandes categorias: (i) técnico-científica; (ii) autogestionária; (iii) interpretativa; (iv) democrático-participativa. Ao analisar as concepções de gestão escolar e observar empiricamente as práticas de gestão, percebe-se que há inúmeras possibilidades e combinações entre os diferentes modelos teóricos. Acrescentando os determinantes econômicos das políticas educacionais governamentais que, de acordo com seu viés político, impõem à escola seu modelo de gestão escolar, essas possibilidades multiplicam-se exponencialmente. Considerando a problemática em questão, apresentam-se apenas as perspectivas técnico-científica e democráticoparticipativa, por se tratar de concepções complementares, a primeira por indicar práticas de educação neoliberais, e a segunda por transvestir-se de uma forma democrática de gestão da educação pública, gratuita, com qualidade e socialmente referencial, mas que esconde formas veladas de terceirização da gestão escolar. 
A concepção técnico-científica é fundamentada na hierarquização dos cargos e funções técnico-administrativas. Baseada em uma organização de inspiração Weberiana, adota regras e procedimentos administrativos com finalidade em si, com vistas a racionalizar o trabalho e a eficácia dos serviços escolares. Por meio da estratégia da divisão técnica do trabalho escolar, busca racionalizar os serviços escolares. Sob essa lógica, o poder político e administrativo é centralizado na figura do diretor do estabelecimento de ensino, sendo as demais funções subordinadas à sua autoridade. A ênfase da gestão ocorre na administração burocrática, por meio do controle das atividades. A comunicação ocorre de forma linear, ou seja, verticalizada (de cima para baixo), com foco nas tarefas que as pessoas devem desempenhar.

A concepção de gestão democrático-participativa ilusoriamente cria a sensação de que as relações de trabalho pedagógico são construídas pelos sujeitos no cotidiano escolar. Acredita-se que os objetivos devem ser assumidos pelo grupo para que a tomada de decisões ocorra de forma participativa, buscando atingir as metas pedagógicas estabelecidas pela comunidade escolar. 0 que essa concepção não coloca em questão é a discussão da função social da escola pública. E por esse motivo, acaba assumindo, mesmo que coletivamente, o ideário de eficiência, eficácia e produtividade forjado pela concepção neoliberal. Compreende o aluno como cliente, a educação como serviço e os profissionais da educação como funcionários.

Na visão neoliberal, conforme assevera Gentili (1996), os sistemas de educação sofrem uma profunda crise de eficiência, eficácia e produtividade. Na concepção tecnocrata neoliberal, não faltam escolas, mas, sim, escolas melhores; não faltam professores, mas, sim, professores qualificados; não faltam recursos, mas, sim, uma melhor redistribuição dos recursos existentes. Assim, é preciso que a escola reestruture suas ações pedagógicas, promovendo e diversificando a oferta educacional nas estratégias de gestão, guiadas pelos conceitos da qualidade total. Para os adeptos desse ideário neoliberal, a escola instituída de forma estatal tende a manter seu caráter ineficiente, uma vez que o Estado vem falhando na democratização da escola pública (GENTILI, 1996).

É possível, para os neoliberais, aceitar que uma sociedade possa ser democrática sem a existência de mecanismos e critérios que promovam uma progressiva igualdade e se concretizem na existência de um conjunto inalienável de direitos sociais e de uma série de instituições públicas nas quais tais direitos se materializam. Para eles, a democracia é, simplesmente, um sistema político que deve permitir aos indivíduos desenvolver sua inesgotável capacidade de livre escolha na única esfera que garante e potencializa a referida capacidade individual: o mercado.

A crise social deriva, fundamentalmente, do fato de que os sistemas institucionais são dependentes da esfera do Estado (da política) e não atuam, eles mesmos, como mercados. 
Isso ocorre, segundo a perspectiva neoliberal, nos campos da saúde, da previdência, das políticas de emprego e, é claro, da educação. Ademais, nessa visão, a cidadania deve basearse na concepção universalizante dos direitos humanos, mas fundamentada nas orientações individuais caracterizadas pelo reconhecimento social e no valor individual empreendedor.

De acordo com Gentili (1996), a lógica econômica do neoliberalismo aplicada à escola a transforma em mercadoria, submetendo o direito subjetivo à educação a perspectivas meritocráticas com foco no mercado de trabalho, o que resulta no direcionamento das políticas públicas educacionais aos interesses do capital. Evidência disso é a forma pela qual o pensamento pedagógico acaba sendo dominado por linguagem empresarial e pelo desenvolvimento de estratégias de gerenciamento e controle dos tempos, espaços e sujeitos no cotidiano escolar.

Sob essa perspectiva a escola torna-se uma empresa capitalista que produz e fornece serviços educacionais sob a lógica da meritocracia e competição, tanto para os estudantes quanto para os profissionais da educação. A gestão educacional baseada na tecnocracia empresarial é guiada pelo pragmatismo instrumental tecnicista voltado para a sbusca de eficiência nos processos burocráticos, valorizando mais o produto do que o processo pedagógico. Sob essa compreensão, a eficácia da educação pode ser mensurada por meio dos resultados de avaliação em larga escala.

Para Gentili (1996), na visão da pedagogia neoliberal a educação tem por finalidade desenvolver competências e habilidades para que os estudantes possam competir no mercado de trabalho atendendo à lógica da classificação e hierarquização meritocrática.

Na esteira dessa compreensão economicista da escola, surge, na década de 1990, a concepção de gestão escolar compartilhada, segundo a qual os profissionais de educação não precisam de fato assumir as instâncias colegiadas de poder no interior dos estabelecimentos, mas somente fazer parte delas. Eles se tornam fiscais do Estado, exercendo uma espécie de gestão colaborativa voluntariosa. Consequentemente, o papel do Estado é esvaziado, e sua função social repassa à iniciativa privada sustentada pela participação voluntarista, isto é, que procura construir relações humanas como políticas de integração conformista e, ao mesmo tempo, confunde gestão escolar como atividade precípua dos profissionais da educação com trabalho voluntário sem remuneração e necessidade de profissionalização.

A concepção de gestão democrática compartilhada acaba por atribuir somente aos profissionais da educação a responsabilidade pelo êxito do trabalho pedagógico ou por seu fracasso, já que a comunidade escolar não participa da elaboração e desenvolvimento da política educacional, seja ela curricular seja de financiamento, sendo apenas sua executora sem os meios adequados para tanto. 
Vê-se que, quando a educação é baseada numa construção fragmentada, numa relação hierarquizada, acaba por objetivar uma gestão compartimentada em que os papéis de poder estão claramente definidos. É assim que Santos (2006) analisa o gerenciamento da escola hoje. Segundo a autora, essa concepção de gestão ainda domina muitos ambientes educacionais, sendo vista como controle de política operacional, organizando-se de forma piramidal - quanto mais na base da pirâmide o indivíduo se localiza, menos poder de decisão ele tem. Diante desse modelo organizacional, deve-se entender que a qualidade da educação é definida e formulada não pelos mais interessados, mas pelos detentores do capital, em projetos político-econômicos medidos pelas avaliações em larga escala, em geral, gestadas no interior de institutos e fundações financiados pelo poder econômico.

\section{GERENCIALISMO DA EDUCAÇÃO PÚBLICA PARANAENSE}

Para entender o que ocorre com o sistema educacional brasileiro, especialmente o paranaense, é de fundamental importância levar em conta as mutações do próprio capitalismo. Elas explicam, em grande medida, a natureza das reformas educacionais em curso no mundo todo. As mudanças de estratégia do capital impactam diretamente nas políticas e modelos educacionais adotados. A educação é um dos braços mais fortes do capital. Como afirma Laval (2004, p. 4), "a educação não traz apenas uma contribuição essencial à economia, ela não é somente um input em uma função de produção, ela é, daqui em diante, compreendida como um fator cujas condições de produção devem ser plenamente submetidas à lógica econômica."

Segundo Laval (2004), há certo entendimento comum entre os autores marxistas que surgem e se consolidam no período entre guerras de uma escola fortemente influenciada pela lógica da gestão empresarial. A escola, é possível concluir, é predominantemente marcada pela lógica do mercado. Ela se justifica e só existe no e para o mercado. A recente reforma do ensino médio aprovada no País é expressão dessa lógica neoliberal.

Pós-Segunda Guerra, período de forte crescimento econômico, a exigência de mão de obra qualificada aumentou em todas as áreas da esfera produtiva, principalmente na indústria pesada. Pari passu, provocou uma complexificação dos níveis de escolarização e especialização. Como assevera Laval (2004, p. १२-१३),

[..] as reformas impostas à escola vão ser [...] cada vez mais, guiadas pela preocupação com a competição econômica entre sistemas sociais e educativos e pela adaptação às condições sociais e subjetivas da mobilização econômica geral. [...] a escola é, cada vez mais, como uma 
empresa entre outras, compelida a seguir a evolução econômica e a obedecer às restrições do mercado.

Os programas e currículos escolares, principalmente do ensino médio e superior, tiveram que se adaptar às necessidades e ao apelo do mercado do trabalho, ou seja, uma escola capaz de formar um efetivo que pudesse preencher as demandas do mercado.

No Paraná, a atual política educacional, sob a direção do Governo Ratinho Júnior, é marcada por essa lógica escola-empresa. Não por acaso, a Fundação Itaú Social assumiu o protagonismo da organização do trabalho pedagógico e da formação continuada de professores. Pedagogia do empreendedorismo, das competências e habilidades, pedagogia administrada, do conhecimento cadastrado e prático, da formação do Homo faber, é disso que trata o Guia de tutoria pedagógica (FUNDAÇÃO ITAÚ SOCIAL, 2014). Trata-se de um projeto de formação continuada financiado pela gestão do atual governo. 0 texto está dividido em cinco partes: Introdução; 0 que é tutoria? Rotinas do trabalho da tutoria pedagógica; Competências do tutor da gestão pedagógica; e para saber mais, apresenta um item destinado a anexos e outro para ficha técnica.

0 texto inicia mostrando as atividades de tutoria da Fundação Itaú Social:

[...] começa em 2009, a partir de pesquisa de campo sobre a reforma do ensino na cidade de Nova York. Ao conhecer e disseminar as melhores práticas experimentadas que pudessem ser aproveitada se aplicadas à realidade das escolas públicas brasileiras, a Fundação Itaú Social desenvolveu, em parceria com a Secretaria de Educação de São Paulo, um piloto em dez escolas na zona Leste da capital. Nele, foi introduzida a tutoria para professores de língua portuguesa e matemática, assim como para gestores pedagógicos. (FUNDAÇÃO ITAÚ SOCIAL, 2014, p. 4, grifo nosso).

Fica evidenciado, no histórico do documento, que a fundação já havia desenvolvido uma experiência de gestão de política educacional com a Secretaria de Educação do Estado de São Paulo e que a SEED-PR, ao adotar os princípios da instituição, utiliza a mesma estratégia metodológica. Tal experiência também ocorreu em Goiás e em algumas redes municipais desse Estado.

A tutoria, de acordo com o documento, funciona como uma "estratégia de formação" que vem sendo aplicada com sucesso em diversos sistemas educacionais, na medida em que permite melhorar a qualidade de aprendizagem dos estudantes. "Seu foco é promover o desenvolvimento profissional do seu tutorado, de forma customizada e sempre com o objetivo de melhorar os resultados de aprendizagem dos alunos." (FUNDAÇÃO ITAÚ SOCIAL, 2014, p. 3). Ainda, “o apoio prático e presencial aos profissionais que atuam no dia a dia 
das escolas tem se mostrado um pilar essencial das reformas educacionais implementadas em diferentes países." (FUNDAÇÃO ITAÚ SOCIAL, 2014, p. 3). Perfeito! Mas como afirmar tal feito de modo tão convincente sem sequer apresentar uma pesquisa, um dado sobre os resultados dessa experiência, seja no Brasil seja fora dele?

A tutoria é entendida como uma

[...] metodologia de formação em serviço, realizada no cotidiano da escola por um profissional mais experiente, que reconhece, valoriza e parte dos conhecimentos e da vivência do tutorado para desencadear o processo de aprendizagem, buscando agregar novos conhecimentos, de caráter prático e modelar (FUNDAÇÃO ITAÚ SOCIAL, 2014, p. 7).

Ela ocorre em dois distintos, mas integrados, níveis: (i) tutoria para gestores pedagógicos; (ii) tutoria de área para professores. A primeira é voltada para a integração e o fortalecimento do trabalho pedagógico dos professores, com foco, principalmente, na orientação dos planos de aula e avaliação do processo de ensino e aprendizagem. Já a segunda visa a qualificar a atividade em sala de aula, mostrando diferentes maneiras de lecionar, ou seja, volta-se às possibilidades múltiplas de realizar a gestão das aulas. Os tutores desenvolvem seu trabalho a partir de alguns princípios, quais sejam: aprendizagem na prática; parceria; customização; protocolos e combinados; intencionalidade e transparência; e foco na aprendizagem dos estudantes, expressões com amplos sentidos utilizadas pelo documento da Fundação Itaú Social.

Os princípios norteadores da prática tutorial, tanto aquela voltada à ação pedagógica quanto a destinada à produção docente, mostram com alguma nitidez a concepção que subjaz esse projeto de formação continuada: gerenciamento e controle da ação docente e pedagógica, com a finalidade de melhorar as notas dos estudantes no ranking dos processos de avaliação em larga escala, como é o caso, por exemplo, do IDEB e da Prova Paraná. Expressões como parceria, customização e protocolos passaram a fazer parte do universo conceitual da educação escolar por meio dos Roteiros de Tutoria Pedagógica (PARANÁ, 2019b). São termos tipicamente do mundo dos negócios, do mundo do mercado livre, da compra e venda de mercadorias e serviços. Isso, por si só, indica a concepção de escola que está em jogo. Ela é vista não mais como um espaço de formação cultural e intelectual, mas como chão de fábrica, como empresa, como lugar para protocolar e cadastrar informações, como instituição prestadora de serviços, escola a serviço da produção em série.

Nesse contexto, os roteiros de tutoria pedagógica (PARANÁ, 2019b) foram estruturados a partir de uma lógica gerencial tipicamente empresarial: produção e controle de qualidade. Ao todo, foram lançados, entre fevereiro e agosto de 2019, pelo Departamento 
de Acompanhamento Pedagógico da SEED-PR, 15 roteiros de tutoria que visam a dirigir o trabalho do tutor pedagógico das escolas, com os seguintes objetivos: observação da organização dos espaços e tempos escolares; observação da integração entre as equipes gestoras, professores, funcionários, alunos e comunidade; diagnóstico das escolas, como as atribuições dos profissionais, equipe gestora, organização do trabalho pedagógico, modo como os professores tratam os alunos e realizam a hora-atividade, formas de avaliação e como usam os dados das avaliações em larga escala para realizar o planejamento das ações pedagógicas da escola. Com isso,

[...] a Equipe Gestora deverá desenvolver uma cultura de organização e trabalho em torno das avaliaç̃̃es, sejam elas: diagnósticas, formativas, em larga escala, etc. e que os resultados dessas avaliações sejam explorados para subsidiar aç̃̃es pedagógicas do professor refletindo não somente em melhorias no processo de ensino, mas, principalmente, na aprendizagem dos alunos. (PARANÁ, 2019b, p. 8).

Os roteiros de tutoria aqui analisados preveem encaminhamentos e orientações para a realização da primeira edição da Prova Paraná, com a definição de ações e estratégias para a melhoria da aprendizagem dos conteúdos presentes nos itens da avaliação:

a) plano de aula e instrumentos avaliativos;

b) organização do conselho de classe;

c) replanejamento das ações a partir dos pontos de atenção observados nos relatórios de acompanhamento pedagógico e que ainda não foram superados;

d) análise pedagógica dos descritores da Prova Paraná, para melhoria da aprendizagem dos conteúdos presentes nos itens da avaliação;

e) Programa Presente na Escola, de acompanhamento de frequência dos alunos na escola;

f) análise dos dados de aprovação, reprovação e abandono da escola, bem como índices de avaliação em larga escala obtidos pela escola;

g) organização dos dias pedagógicos de estudos e planejamento;

h) reorganização do calendário escolar para reposição de aulas da greve dos professores;

i) nivelamento do início do segundo semestre; 
j) planejamento das ações a serem realizadas pela escola em preparação à Prova Brasil.

Como a estratégia de tutoria da SEED-PR está centrada no modelo empresarial de gestão de pessoas, elegeram-se seis atores, compreendidos como sujeitos do processo pedagógico, aos quais estão destinados os procedimentos da atuação de coaching pedagógico no modelo preconizado pela Fundação Itaú Social, descrito anteriormente. São eles: tutor; equipe gestora; equipe pedagógica; professores; alunos/estudantes; e pais/comunidade. A seguir, passa-se a apresentar evidências da ação de controle gerencial desses sujeitos, uma vez que os roteiros de tutoria seguem um padrão prescritivo que deve ser atendido pelo tutor e demais sujeitos do processo pedagógico.

Os roteiros não são apenas checklists, mas têm a finalidade de nortear/guiar a ação do tutor, que deve se apropriar deles antes de se dirigir à escola. Recomenda-se que não se façam anotações durante o processo de tutoria e que o roteiro não seja disponibilizado aos demais sujeitos do cotidiano escolar, para evitar que eles estejam preparados para responder a eventuais questionamentos do tutor, cujas atribuições, descritas nos 15 roteiros de tutoria, são expressas especialmente pelos seguintes verbos: discutir, orientar, instigar, mobilizar, organizar, exercitar, auxiliar, repassar, perguntar e verificar - sendo verificar a ação mais frequente a ser desenvolvida.

As ações do tutor pedagógico vão desde diagnosticar as condições de funcionamento das escolas, como, por exemplo, verificar como são organizados os espaços e tempos escolares, como e quando os professores realizam a hora-atividade, como os pedagogos acompanham e orientam $\circ$ trabalho dos professores, seus planos e aulas, avaliações, etc. 0 tutor pedagógico também é responsável por repassar informações acerca das avaliaç̃̃es em larga escala, acompanhar sua aplicação e trabalhar seus resultados com a equipe gestora. Deve exercitar a escuta ativa, por meio da observação, questionamento e feedback, de modo a criar confiança em seus interlocutores no cotidiano escolar.

0 início do trabalho do professor mentor/tutor requer muita sensibilidade, e os avanços são lentos. A princípio nós não sabemos exatamente como será a pauta detalhada de nosso trabalho na escola. Em nossos primeiros encontros com o diretor e os professores, olhamos o básico: examinamos e discutimos com eles os trabalhos dos alunos, o currículo, nos oferecemos para planejar aulas junto com eles... A partir daí, vamos ganhando sua confiança, alguns começam a pedir dicas, a se interessar por uma parceria conosco, nos convidam a planejar, visitar uma aula ou dar aula junto com eles. (GALL; GUEDES, 2009, p. 49, grifo nosso). 
0 guia de tutoria pedagógica elaborado pela Fundação Itaú Social (2014) está em consonância com o documento A reforma educacional de Nova York (GALL; GUEDES, 2009). Nele, está previsto que o início do trabalho consiste em identificar os pontos fortes e aqueles que precisam ser desenvolvidos e a necessidade daquilo que é denominado customização da tutoria - a aproximação com o tutorado colabora para romper possiveis barreiras do trabalho e "ganhar sua confiança". Isso possibilita traçar um plano inicial de trabalho a partir da fotografia oriunda da atividade in loco, contando com a descrição e análise do tutorado, principalmente com relação àquilo que corresponde aos elementos observados e dados obtidos nos sistemas de avaliação interno e externo.

0 tutor deve instigar e orientar a equipe gestora para organização do préconselho, do conselho e do pós-conselho de classe, fazendo levantamento de dados e divulgando seus resultados, bem como o plano de ação da escola. Em consonância com o guia, encontra-se um quadro que trata do currículo e das expectativas de aprendizagem e avaliação, que descreve os pontos para o gestor construir o plano de ação, cujo elemento central deve ser a avaliação.

A partir da análise dos 15 roteiros de tutoria pedagógica emanados da SEED-PR (até o momento desta análise), foi possível traçar um parâmetro das exigências da mantedora que recaem sobre a equipe gestora das escolas estaduais do Paraná, composta pelo diretor, diretor auxiliar e equipe pedagógica (pedagogos). Por exemplo, é responsabilidade da equipe gestora da escola elaborar e manter atualizado o plano de ação da escola. Para isso, devese ter profundo conhecimento dos dados das avaliações externas realizadas pelos alunos da escola e das metas de crescimento do resultado dessas avaliações estabelecidas pelos organismos oficiais de gestão da política educacional.

De acordo com o documento de Nova lorque e a adaptação feita pela Fundação Itaú Social para a realidade brasileira, é necessário acompanhar o progresso dos alunos "[...] como foi feito em Nova York, onde os alunos são avaliados a cada dois meses e o aproveitamento de cada um é analisado por equipes de professores." (GALL; GUEDES, 2009, p. 23). Nesse sentido, a SEED-PR lançou, no dia 22 de agosto de 2019, uma consulta sobre o processo de periodização do processo avaliativo para padronizar a forma de fechamento das avaliações, sendo oferecidas à comunidade escolar as opções bimestre ou trimestre. Diante dos resultados, todas as escolas da rede estadual deverão adequar seus sistemas avaliativos o quanto antes.

0 documento-guia defende e orienta que o diretor deve ser o líder do processo de gestão, devendo ser responsável pela organização do trabalho pedagógico e pela integração entre a equipe gestora, professores, alunos e comunidade. Da equipe gestora é cobrada a definição de ações para melhoria dos índices de aprendizagem aferidos pelas avaliações internas e externas. Para isso, deve prever e promover ações constantes com professores 
e alunos, a fim de trabalhar com os resultados das avaliações, especialmente as de larga escala, que mensuram a proficiência dos discentes em língua portuguesa e matemática. Ainda, deve promover ações para que as demais disciplinas do currículo escolar desenvolvam os respectivos descritores das avaliações, para melhorar o desempenho dos alunos nas avaliações em larga escala, como, por exemplo, a Prova Paraná, realizada em três etapas durante o ano letivo.

Outro foco de ação da equipe gestora, cobrado pelo tutor, é com relação aos professores e ao trabalho docente. A preocupação com a ocupação dos professores na hora-atividade está voltada para o cumprimento do horário na escola, com a realização de atividades como planejamento de aulas, elaboração de avaliações dos alunos e estudo dos índices das avaliações em larga escala, especialmente da Prova Paraná. Nos roteiros de tutoria, é possível observar a insistência para que os professores elaborem planos de aula para ministrar boas aulas. No entanto, os roteiros não esclarecem quais seriam os parâmetros de uma boa aula.

Há, ainda, nos roteiros uma forte insistência na metodologia de realização do conselho de classe como sendo um elemento fundamental para que a equipe gestora possa diagnosticar os problemas de ensino e aprendizagem a tempo de poder solucioná-los. Há a determinação de que a equipe de gestão realize o conselho de classe em três etapas distintas: o pré-conselho de classe, o conselho de classe propriamente dito e o pós-conselho de classe. No pré-conselho, o roteiro determina a realização de uma série de procedimentos diagnósticos com o uso de planilhas on-line a serem preenchidas pelos professores; no conselho de classe, os professores traçam soluções a partir do diagnóstico; e no pósconselho, a equipe pedagógica atua para fazer cumprir os encaminhamentos dados no conselho de classe.

Portanto, observa-se a forte determinação de responsabilização da equipe gestora pelo sucesso ou fracasso do processo de ensino e aprendizagem, sendo o sucesso visto como aferição de boas notas obtidas pelos alunos nas avaliações internas e em larga escala, e o fracasso concebido como baixo rendimento nos índices das mesmas avaliações.

Outro agente presente nos roteiros de tutoria é a equipe pedagógica, composta exclusivamente por profissionais formados em Pedagogia e parte integrante da equipe gestora. Observa-se certa sobreposição de funções atribuídas a ela e à equipe gestora, o que acaba por esvaziar a importância do trabalho do profissional formado em Pedagogia no interior das escolas estaduais do Paraná. Dos 15 roteiros de tutoria, cinco não mencionam o trabalho da equipe pedagógica nas ações da tutoria, e nos demais, verifica-se a minimização da importância do trabalho do pedagogo, de modo que acaba sendo visto como função auxiliar à direção da escola, perdendo, assim, sua função precípua de organizar o trabalho pedagógico. Sua função é fragmentada e restrita a ações pontuais de acompanhar a entrada e a saída 
dos alunos; realizar o acompanhamento das atividades dos professores durante a horaatividade; conhecer os resultados das avaliações externas, o plano de ação e suas metas e os índices das avaliações externas referentes aos alunos da escola; promover a integração entre professores e alunos; verificar os planos de aula e as avaliações elaboradas pelos professores; bem como acompanhar as aulas dos professores para sugerir melhorias em sua prática docente. Perde-se a compreensão do todo necessário à organização do trabalho pedagógico.

0 Guia de Tutoria Pedagógica (FUNDAÇÃO ITAÚ SOCIAL, 2014) corrobora a função da coordenação pedagógica que se encontra nos roteiros, no sentido de que deve aproveitar situações como problemas comportamentais dos estudantes. É necessário acompanhar in loco o trabalho do professor e depois oferecer um feedback, o qual deve ser pensado se utilizando de estratégias discursivas para diminuir possíveis resistências. É relevante entender que o documento apresenta o diretor como líder da coordenação pedagógica, devendo criar condições para que os pedagogos exerçam a função deliberada, em busca de efetivar o projeto pensado e escrito no plano de ação. Com os roteiros de tutoria apontando como atribuições do pedagogo atividades fragmentadas entre gestão e atuação pedagógica, perde-se a característica coletiva da organização do trabalho pedagógico, ficando o profissional refém das ações desenvolvidas pela equipe gestora.

Os professores também são considerados atores/sujeitos do processo pedagógico nos roteiros de tutoria, sendo a determinação de ações da equipe gestora a eles enorme e com conotação de forte controle. Começa-se pela exigência estabelecida no primeiro roteiro para que o tutor verifique se os professores são integrados à escola, se tornam a escola atrativa aos alunos, como procedem na troca das aulas, se cumprem os horários, como recepcionam os alunos em suas salas, como realizam a hora-atividade e se as utilizam para estudos, planejamentos e elaboração e correção das avaliações, se preparam suas aulas, se participam das reuniões pedagógicas, se respeitam a legislação vigente, se compreendem a importância das avaliações externas e seus índices, se conhecem e cumprem o plano de ação da escola e suas metas, etc. Com tantas determinações de verificação, o trabalho da tutoria pedagógica configura-se muito mais como sendo de bedel do que de orientador do trabalho pedagógico.

No documento A reforma educacional de Nova York (GALL; GUEDES, 2009), argumentase que a mudança requer a presença de pessoas para qualificar os professores e gestores em atividades instrucionais. Por isso, é necessário focar na metodologia, pois os elementos oriundos dos dados revelam, segundo essa perspectiva, um problema que pode ser solucionado com estratégias metodológicas, sendo estas de responsabilidade dos professores. Eles precisam de uma gestão treinada para identificar os problemas com as práticas docentes evidenciadas com os dados e trabalhar com técnicas que possam revertê-los. 
Em casos de identificação de alguma dificuldade do professor com alguma turma, o roteiro de tutoria recomenda que integrantes da equipe pedagógica assistam às aulas do professor, a fim de realizar as intervenções necessárias e diagnosticar as possiveis fragilidades, como falta de planejamento das aulas, aulas desconectadas do cotidiano dos alunos, dificuldades do professor na gestão de sala de aula e falta de engajamento dos alunos (PARANÁ, 2019a).

Observa-se que os roteiros de tutoria seguem a lógica do gerenciamento empresarial, que visa a premiar aqueles que apresentam a produção de bons resultados e punir os que não produzem de acordo com o esperado.

Os professores e diretores que melhoram o desempenho de seus alunos recebem bônus e promoções. Aqueles que persistentemente fracassam em fazê-lo são substituídos. [...] As escolas com pior desempenho são fechadas e seus prédios, ocupados por novas escolas com novos quadros de funcionários. (GALL; GUEDES, 2009, p. 23).

É importante registrar que a prática de fechamento de escolas com problemas de desempenho, frequência ou rendimento já é uma realidade na atual administração estadual, perceptível nos dados sistematizados a partir dos registros retirados do trabalho de tutoria. Há, nesse sentido, a constatação de que resultados indesejados no processo produtivo devem modificar a metodologia; por exemplo, quando da realização da Prova Paraná e análise dos seus índices, os professores de Língua Portuguesa e Matemática foram chamados a interromper o trabalho que vinham realizando de acordo com seu planejamento e utilizar os cadernos de exercícios disponibilizados pela mantenedora, assim como revisar com os alunos os conteúdos das provas aplicadas.

Com relação ao conselho de classe, os roteiros de tutoria também fizeram valer uma série de encaminhamentos metodológicos que deveriam ser adotados pelas escolas e seus professores. Determinam que os tutores acompanhem a realização do conselho de classe como observadores, a fim de identificar fragilidades a ser corrigidas.

Outra forte interferência do roteiro de tutoria ocorreu no processo de Registro de Classe On-line (RCO), no qual os professores devem registrar a cada aula a frequência dos alunos, o conteúdo ministrado, a realização de avaliações e recuperações, bem como anotações acerca do desempenho individual de cada discente. É a partir do RCO que a mantenedora consegue realizar o acompanhamento on-line de todos os registros escolares realizados pelos professores e equipe pedagógica. Muitas escolas não possuem internet de alta velocidade, o que obriga muitos professores a utilizar seu próprio pacote de dados para enviar os registros. 
Ainda, com o período de greve dos profissionais da educação por melhores condições de trabalho e salário, um dos relatórios de tutoria determinou a elaboração do calendário de reposição das aulas não dadas e o acompanhamento das reposições pelos tutores, evidenciando a forte intervenção da mantenedora na autonomia pedagógica das escolas por meio da ação da tutoria.

Dos 15 roteiros, apenas sete mencionam brevemente alguma preocupação com a comunidade escolar, indicando o desinteresse da mantenedora pelo caráter democrático da educação, quando se tem a presença da comunidade escolar, representada especialmente pelos pais e responsáveis, na tomada de decisões e na organização do trabalho pedagógico. Sabese que, no cotidiano escolar, as instâncias colegiadas, como a Associação de Pais, Mestres e Funcionários, o Conselho Escolar e o Grêmio Estudantil, orientadas de acordo com princípios democráticos, podem ser poderosas ferramentas de gestão democrática da educação. Certamente, quando os roteiros de tutoria negligenciam esses segmentos da comunidade escolar, não o fazem por puro esquecimento. Tais evidências já dão a possibilidade de outra investigação.

Quanto aos estudantes, a preocupação da mantenedora evidenciada nos roteiros refere-se aos resultados das avaliações internas e externas à escola, ou seja, é possível inferir que são concebidos como objetos do processo de avaliação e não como sujeitos da educação. A preocupação com os índices de frequência e abandono, aprovação e reprovação permeia as ações da tutoria pedagógica nas escolas, com grande ênfase nas três etapas da Prova Paraná. Esses elementos estão presentes no guia de tutoria, que apresenta que "tutor e tutorado constroem uma relação de parceria e corresponsabilidade, com foco no desenvolvimento da prática do tutorado, de forma customizada, sempre com o objetivo de melhorar os resultados de aprendizagem dos alunos." (FUNDAÇÃO ITAÚ SOCIAL, 2014, p. 7, grifo nosso).

Os estudantes são concebidos como objetos da avaliação de resultados, constatação que pode ser evidenciada pelo episódio no qual, por ordem da mantenedora, os tutores foram enviados às escolas para fazer a verificação in loco dos alunos que estavam com grande número de faltas ou que já não estavam frequentando regularmente a escola. 0 evento foi motivado pela coleta de dados que o Censo Escolar faria diretamente do Sistema Estadual de Registro Escolar (SERE). Caso os alunos faltosos ou desistentes fossem identificados pelo Censo Escolar, poderia haver uma queda do IDEB das escolas estaduais do Paraná. Por ordem da mantenedora, após a verificação, os alunos que não possuíam frequência regular foram retirados do sistema e, consequentemente, não identificados pelo Censo Escolar, gerando um crescimento artificial do IDEB de 2019. Posteriormente, os alunos foram reinseridos no SERE. 
Não se quer negar o mérito da necessidade do trabalho pedagógico, tendo em vista a melhoria do processo de ensino e aprendizagem e a contenção da evasão escolar e reprovação dos alunos. No entanto, as formas de encaminhamento da organização desse processo, pautadas no gerencialismo técnico-científico, não alteram as condições do trabalho pedagógico. Roman (1999), em pesquisa realizada no final da década de 1990, já asseverava que o Estado neoliberal se apresenta como mínimo quando se trata de financiar a educação pública, dando condições de trabalho, e máximo quando define a forma de controle dos profissionais da educação e da organização do conhecimento oficial nas instituições, estabelecendo mecanismos verticalizadores e antidemocráticos de avaliação do sistema escolar.

\section{CONSIDERAÇÕES FINAIS}

0 neoliberalismo combina com crise, gera crises sociais e econômicas e se nutre delas. Desde os anos 1970, a lógica do sistema em curso é a mesma: não questionar as raízes dos problemas que causam a crise, senão combatê-la com a mesma receita, ou seja, austeridade com os gastos públicos, privatização das empresas estatais, diminuição da intervenção do Estado na economia e no suprimento dos serviços essenciais, como saúde, educação e transporte (terceirização dos serviços em geral), e manutenção e incentivo à especulação financeira (transferência e aplicação de dinheiro no sistema financeiro). Mesmo que isso não funcione, isto é, mesmo que não crie condições de estabilidade social, mesmo que isso agite/desequilibre o sistema financeiro e o torne mais propício a colapsos iminentes, mesmo que aumente os protestos e movimentos de contestação, mesmo que provoque devastação da natureza, guerras de toda ordem, desemprego e destruição do tecido industrial, a lógica deve permanecer: aguçar cada vez mais a concorrência entre os indivíduos e entre os grupos corporativos, ampliar a arrecadação via impostos, taxando bens, serviços e remuneração do trabalhador assalariado. Por isso, a reforma da previdência, no caso brasileiro, tornou-se tão importante para as elites.

Para compreender a interferência neoliberal na educação, é necessário entender o conceito de descentralização apresentado na Constituição Federal de 1988. Pode-se entendê-la a partir da lógica economicista-instrumental, em que ocorre a transferência da responsabilidade do Estado pela oferta educacional, diminuindo gastos públicos, entendendo que o investimento em políticas sociais não seria necessário.

As atuais políticas educacionais paranaenses e a recente reforma do ensino médio mostram a necessidade de manter o embate contra a escola dual e sua concepção 
técnico-científica e mercantil, uma vez que está longe de ser superada, quiçá a conquista de uma sociedade/educação para além do capital. 0 estado do Paraná está em um processo avançado de implementação da proposta de controle gerencial, uma vez que a equipe gestora de cada escola deve se preocupar fundamentalmente com os resultados do processo educacional mensurados por meio dos índices de avaliação interna e externa, de aprovação, reprovação e evasão escolar dos alunos.

Ao adotar os princípios e metodologias de gestão de política pública ditados pelos institutos e fundações empresariais, coloca-se em xeque o princípio da gestão democráticoparticipativa. Há evidências de que os roteiros de tutoria pedagógica são elaborados por assessores diretamente vinculados a institutos e fundações financiados pelo meio empresarial e sistema financeiro. Observa-se, como consequência, que a gestão da política educacional paranaense é terceirizada de acordo com os interesses do mercado, questão que necessita ser mais bem investigada e aprofundada em futuras pesquisas.

\section{REFERÊNCIAS}

ANDRADE, S. V. R. As políticas educacionais do estado do Paraná no período de 2003 a 2010 e o desenvolvimento profissional dos professores de matemática. Dissertação (Mestrado em Educação) Universidade Estadual de Maringá, Maringá, 2012. Disponivel em: http://repositorio.uem.br:8080/jspui/ bitstream/1/4409/1/000200267.pdf. Acesso em: 17 abr. 2020.

BRASIL. Constituição. República Federativa do Brasil de 1988. Brasília, DF: Senado Federal, 5 out. 1988.

DAMETTO, J. Avaliação em larga escala e a objetivação da qualidade educacional: controvérsias em torno da fabricação discursiva da qualidade na educação básica. 2017. Tese (Doutorado em Educação) - Universidade de Passo Fundo, Passo Fundo, 2017. Disponível em: http://tede.upf.br/jspui/ bitstream/tede/1239/2/2017JarbasDamettoTese.pdf. Acesso em: 16 abr. 2020.

FUNDAÇÃO ITAÚ SOCIAL. Guia de tutoria pedagógica. São Paulo: Fundação Itaú Social, 2014.

GALL, N.; GUEDES, P. M. A reforma educacional de Nova York: possibilidades para o Brasil. São Paulo: Fundação Itaú Social, 2009.

GENTILI, P. Neoliberalismo e educação: manual do usuário. In: SILVA, T. T.; GENTILI, P. (org.). Escola S.A.: quem ganha e quem perde no mercado educacional do neoliberalismo. Brasília, DF: CNTE, 1996. p. 9-49.

GOMIDE, A. G. V. Formação de Professores no Brasil: Precarização, desqualificação e intervenção da UNESCO nas políticas educativas a partir de 1990. In: ENCONTRO DE PESQUISA EM EDUCAÇÃO DA REGIÃO SUL, 8., 2010, Londrina. Anais [...] Londrina, 2010. v. 1. p. 1-14. Disponível em: http://universidadetuiuti.utp. $\mathrm{br} /$ Cadernos_De_Pesquisa/pdfs/cad_pesq11/7_politicas_da_unesco_cp11.pdf. Acesso em: 17 abr. 2020. 
HORN, G. B. Por uma mediação praxiológica do saber filosófico no ensino médio: Análise e Proposição a partir da Experiência Paranaense. 2002. Tese (Doutorado em Educação) - Universidade Estadual de São Paulo-Faculdade de Educação, São Paulo, 2002.

JESUS, A. 0.; GOMIDE, A. G. V. Políticas de formação de professores: alguns apontamentos sobre a formação em nível médio, no Estado do Paraná, a partir do ano de 2003. [S. l.: s. n., 2008. Disponível em: http://www.gestaoescolar.diaadia.pr.gov.br/arquivos/File/producoes_pde/md_maria_aparecida_oliveira_jesus.pdf. Acesso em: 17 abr. 2020.

LAVAL, C. A escola não é uma empresa: o neoliberalismo em ataque ao ensino público. Londrina: Planta, 2004.

LIBÂNEO, J. C.; OLIVEIRA, J. F.; TOSCH, M. S. Educação escolar: políticas, estrutura e organização. 10. ed. São Paulo: Cortez, 2012.

MENDES, A. A. P. A construção do lugar da filosofia no currículo do ensino médio: análise a partir da compreensão dos professores de filosofia da escola pública paranaense. 2008. Dissertação (Mestrado em Educação) - Universidade Federal do Paraná, Curitiba, 2008. Disponível em: https://repositorio. uninter.com/handle/1/357. Acesso em: 14 abr. 2019.

NODA, M.; GALUCH, M.T.B. Políticas públicas de educação no ensino básico do Estado do Paraná: da dívida social à formação para o mercado (1980-2000). Revista HISTEDBR On-line, v. 18, p. 545-569, 2018.

PARANÁ. Secretaria de Estado da Educação. Inexigibilidade de Chamamento Público para a formalização do Acordo de Cooperação Técnica com o Instituto Compartilhar. Curitiba: SEED, 2019a. Disponível em: http://www.educacao.pr.gov.br/Pagina/Acordos-de-Cooperacao. Acesso em: 14 abr. 2019. PARANÁ. Secretaria de Educação. Roteiros de tutoria pedagógica. Curitiba: SEED, $2019 \mathrm{~b}$.

PARANÁ. Secretaria de estado da Educação. Termo de Convênio de Cooperação Técnica $n^{\circ}$ 201900006/2019 - SEED e SESC. Curitiba: SEED, 2019c. Disponivel em: http://www.educacao.pr.gov.br/ Pagina/Acordos-de-Cooperacao. Acesso em: 14 abr. 2019.

ROMAN, M. D. Neoliberalismo, política educacional e ideologia: como ilusões de neutralidade da pedagogia como técnica. Psicologia USP, São Paulo, v. 10, n. 2, p. 153-187, 1999. Disponível em: http://www. scielo.br/scielo.php?script=sci_arttext\&pid=S0103-65641999000200011\&lng=en\&nrm=iso. Acesso em: 17 abr. 2020.

SANTOS, A. L. F. Gestão democrática da escola: bases epistemológicas, políticas e pedagógicas. [S. l]: Anped, 2006. Disponivel em: http://www.anped.org.br/sites/default/files/gt05-2114.pdf. Acesso em: 9 jun. 2019.

SAVIANI, D. Políticas educacionais em tempos de golpe: retrocessos e formas de resistência. Roteiro, $v$. 45, 2020. 
SOUSA, S. E. A gestão educacional no Paraná 2011-2013. 2013. 2013. Dissertação (Mestrado em Sociedade, Estado e Educação) - Universidade Estadual do Oeste do Paraná, Cascavel, 2013. Disponível em: http://tede.unioeste.br/handle/tede/865. Acesso em: 14 abr. 2020.

TIRADENTES, A. F. Politica, trabalho e conhecimento no "novo ensino médio". Revista Trabalho $\mathrm{Ne}^{-}$ cessário, v. 5, n. 5, jun. 2018. Disponível em: https://periodicos.uff.br/trabalhonecessario/article/ view/4623/4259. Acesso em: 17 abr. 2020.

VIEIRA, W. J. 0 ensino de filosofia e o uso do texto clássico de filosofia: análise a partir das escolas públicas paranaenses de ensino médio. Dissertação (Mestrado em Educação) - Universidade Federal do Paraná, Curitiba, 2012. Disponível em: https://acervodigital.ufpr.br/bitstream/ handle/1884/29273/R\%20-\%20D\%20-\%20WILSON\%20JOSE\%20VIEIRA.pdf. Acesso em: 17 abr. 2020.

Endereço para correspondência: Avenida Constituição, 1759, $1^{\circ}$ andar, Boa Vista, São José do Rio Preto, São Paulo, Brasil; ademir.m@uninter.com

Roteiro, Joaçaba, U. 45, p. 1-24, jan./dez. 2020 | e22393 |E-ISSN 2177-6059 
